\title{
AVALIAÇÃO DA APRENDIZAGEM: REFLEXÕES DOS PROFESSORES DE EDUCAÇÃO FÍSICA NA EDUCAÇÃ̃ BÁSICA
}

\author{
EVALUACIÓN DEL APRENDIZAJE: REFLEXIONES DE LOS MAESTROS DE \\ EDUCACIÓN FÍSICA EN EL EDUCACIÓN BÁSICA
}

\section{LEARNING EVALUATION: REFLECTIONS OF PHYSICAL EDUCATION TEACHERS IN THE BASIC EDUCATION}

\author{
Maria Petrília Rocha FERNANDES ${ }^{1}$ \\ Maria Adriana Borges dos SANTOS $^{2}$ \\ Kessiane Fernandes NASCIMENTO ${ }^{3}$ \\ Manoela de Castro Marques RIBEIRO ${ }^{4}$ \\ Heraldo Simões FERREIRA ${ }^{5}$
}

RESUMO: Este estudo tem como objetivo analisar a concepção dos professores na Educação Física escolar sobre avaliação da aprendizagem. O caminho metodológico caracterizou-se por uma investigação de campo, cuja abordagem é qualitativa. Os participantes foram oito professores de Educação Física da rede estadual de ensino Municipal de Sobral/CE. Os dados foram coletados por meio de entrevista estruturada e analisados usando a análise temática de Minayo (2014). Constatou-se nos resultados que apesar das mudanças propostas nas últimas décadas no que se refere ao entendimento sobre avaliação da aprendizagem, ainda é possível identificar professores que possuem uma compreensão fragilizada, frente a uma racionalidade técnica, com concepções utilitaristas do processo avaliativo. Em meio a conclusões inacabadas, propõe-se ações mais efetivas para a formação dos professores, possibilitando assim, que através do exercício reflexivo no ato de ensinar se atendam às reais expectativas da avaliação da aprendizagem.

PALAVRAS-CHAVE: Escola. Educação física. Ensino médio.

RESUMEN: Este estudio tiene como objetivo analizar la concepción de los maestros en la Educación Física escolar sobre evaluación del aprendizaje. El camino metodológico se

${ }^{1}$ Universidade Estadual do Ceará (UECE), Fortaleza - CE - Brasil. Mestre em Ensino na saúde e professora da Educação Básica. ORCID: <http://orcid.org/0000-0001-9965-639X>. E-mail: petrilia@ hotmail.com

${ }^{2}$ Universidade Estadual do Ceará (UECE), Fortaleza - CE - Brasil. Doutoranda em Educação e professora da Educação Básica. ORCID: <http://orcid.org/0000-0003-2090-2864>. E-mail: madriborges@hotmail.com

${ }^{3}$ Universidade Estadual do Ceará (UECE), Fortaleza - CE - Brasil. Mestre em Educação na Universidade Estadual do Ceará - UECE. ORCID: <https://orcid.org/0000-0002-5731-759X>. E-mail: kessianefn@ hotmail.com

${ }^{4}$ Universidade Estadual do Ceará (UECE), Fortaleza - CE - Brasil. Especialista em Atividade Física para grupos especiais. Graduada em Educação física. ORCID: 〈https://orcid.org/0000-0003-2096-6745>. E-mail: manuelaribeiro86@hotmail.com

${ }^{5}$ Universidade Estadual do Ceará (UECE), Fortaleza - CE - Brasil. Pós-Doutor em Educação Física Escolar no programa de Pós-Graduação em Desenvolvimento Humano e Tecnologias na Universidade Estadual de São Paulo (UNESP). Professor do Programa de Pós-Graduação em Educação da UECE. ORCID: <http://orcid.org/00000003-1999-7982>.E-mail: heraldo.simoes@uece.br 
caracterizó por una investigación de campo, cuya abordaje es cualitativa. Los participantes fueran ocho maestros de educación física de la red estadual de enseño municipal de Sobral/CE. Los datos fueran recogidos por medio de una entrevista estructurada y analizados utilizando el análisis temática de Minayo (2014). Se ha constatado en los resultados que a pesar de los cambios propuestos en las ultimas décadas, en lo que se refiere a el entendimiento sobre evaluación de aprendizaje, todavía es posible identificar maestros que tienen una compreensión socavada delante una racionalidad técnica, con concepciones ultilitaristas del proceso evaluativo. En medio a conclusiones inacabadas, se propone acciones más efectivas para la formación de los maestros, posibilitando así, que mediante del ejercício reflexivo en el acto de enseñar se atendan a expectativas reales de la evaluación del aprendizaje.

PALABRAS CLAVE: Escuela. Educación física. Enseño médio.

ABSTRACT: This study has as an objective to analyze the conceptions of scholar Physical Education teachers about the learning evaluation. The methodological path was characterized by a field investigation, which approach is qualitative. The participants were eight Physical Education teachers from the of Sobral's state education system. The data was collected through a structured interview and analyzed using the thematic analyze of Minayo (2014). It was verified in the results that despite the proposed changes in the last decades regarding to understanding about learning evaluation, still is possible to identify teachers that have weak understanding against a technical rationality, with utilitarian conceptions of evaluative process. Amid the unfinished conclusions, It is proposed actions more effectives to the teacher training, thus enabling, that through the reflexive exercise in the act of teaching serve to the real expectations of the learning evaluation.

KEYWORDS: School. Physical education. High school.

\section{Introdução}

A avaliação escolar, nos últimos anos, vem crescendo como objeto de reflexão do processo de ensino aprendizado, e, desta forma, se consolidando como um meio e não um fim do trabalho educacional. É através da avaliação escolar que muitas instituições educacionais tornam melhor o ensino que ofertam, e, assim, melhoram o aprendizado de seus educandos (PERRENOUD, 1999).

No entanto, para o estudioso Luckesi (2003) a prática escolar predominante, hoje, se realiza dentro de um modelo de educação que se apresenta como um mecanismo de conservação e reprodução da sociedade. Esse modelo conservador da sociedade implica em três pedagogias diferentes: a pedagogia tradicional, centrada na transmissão de conteúdo e na pessoa do professor; a pedagogia escolanovista, cuja produção do conhecimento é situada no educando; e a pedagogia tecnicista, na qual as técnicas de transmissão e apreensão dos conteúdos visão o 
princípio do rendimento. Porém com um mesmo objetivo: conservar a sociedade na sua configuração. Essas três pedagogias, por estarem dentro desse modelo social conservador, sendo mais intenso a primeira e a última, inibem tentativas de transcendê-lo e superá-lo.

Em consonância com Libâneo (1994), percebe-se que a avaliação tem sido tomada como o ato de aplicar provas, atribuir notas e classificar os alunos; sendo, portanto, reduzida à cobrança daquilo que o aluno memorizou. A avaliação precisa ser entendida de uma maneira muito mais ampla, posto à complexidade que a circunda, pois se configura de extrema importância no processo de ensino-aprendizagem. Visto que avaliar é mediar esse processo, acompanhado seu progresso concomitante ao seu desenrolar, oferecer medidas de recuperação, promover habilidades, acompanhar cada aluno em seus avanços.

Considera-se que para o processo de ensino-aprendizagem na educação avançar em qualidade é preciso compreender a avaliação como instrumento primordial nesse sistema, utilizada da melhor forma possível, percebendo as necessidades de seu corpo docente e discente, propondo ações mais efetivas para a formação dos professores, e possibilitando assim, que através do exercício reflexivo do ato de ensinar se atendam às reais expectativas da instituição pertencente.

A Educação Física, no decorrer de sua história, sofreu influências de várias tendências e abordagens que interferiram na prática pedagógica dos profissionais desta área, e consequentemente, as práticas avaliativas foram sendo aliadas as diversas abordagens pelos quais a disciplina passou, sendo adaptadas às necessidades e particularidades de cada sistema de ensino.

Neste sentido, os estudos da avaliação em Educação Física ganham fôlego em meados da década de 1970, com o intuito de criar práticas avaliativas fidedignas e objetivas. Com o passar das décadas, a construção do conhecimento na área indicou novas possibilidades e novos referenciais, sobretudo nacionais, pautados na ética, nas diferenças e na avaliação formativa.

A Educação Física escolar, parte integrante do projeto educativo escolar, não pode estar distanciada das discussões referentes à avaliação. Nesse sentido, é importante compreender melhor o lugar das práticas avaliativas no âmbito dessa disciplina incumbida de tratar pedagogicamente os conteúdos/temas da cultura corporal de movimento (BRACHT, 1992).

Apesar dos avanços teóricos, trabalhos como o de Hoffmann (2003), na Educação em geral, e de Alegre (1993), na Educação Física, têm demonstrado uma insatisfação por parte dos professores quanto à prática avaliativa no processo ensino-aprendizagem, o que traz à tona a 
necessidade de refletirmos acerca do que está sendo produzido no cotidiano escolar, principalmente nas aulas de Educação Física.

A Educação Física vem enfrentando uma tendência da educação contemporânea que é a caducidade dos saberes, bem como, a revisão constante de suas práticas e metodologias. $\mathrm{O}$ mesmo se aplica diretamente à avaliação escolar, que, durante muitos anos, foi apenas uma forma de punição e metrificação dos educandos, e, nos dias atuais, vem sendo colocada em outra postura dentro do processo educacional (HOFFMANN, 2003).

A partir das questões supracitadas, surge o interesse em pesquisar como a avaliação escolar inserida na disciplina de Educação Física pode vir a contribuir para a efetivação de um trabalho pedagógico onde professor e o educando dialoguem, interajam e aprendam mediados pela função gnosiológica, e ainda, percebam-se dentro do processo de ensino. Desse modo, este trabalho tem o objetivo de analisar a concepção dos professores na Educação Física escolar sobre avaliação da aprendizagem.

Portanto, sendo a Educação Física um componente curricular obrigatório da educação básica deve comprometer-se com a formação integral do aluno, deve, portanto, estruturar práticas avaliativas que contribuam para o ensino-aprendizagem. Assim, acredita-se na importância desta pesquisa como possibilidade de contribuir com os docentes, para refletir epistemológica sobre o trato pedagógico, com foco na avaliação do ensino-aprendizagem, tendo-se em vista, que a avaliação possui fins de melhoria da aprendizagem e da qualidade do ensino, na perspectiva da avaliação formativa, proposta por Hadji (2001) e Perrenoud (1999), pois se sabe que durante muito tempo a avaliação, teve como pressuposto a pedagogia do exame, ou seja, a nota.

\section{Concepções de avaliação}

A avaliação da aprendizagem tem sido objeto de uma vastíssima literatura especializada nas pesquisas educacionais, assim como tem se mostrado presente em temas de inúmeras discussões no cenário atual. Isso tem gerado diversas interpretações sobre o conceito de avaliação dentro do contexto educacional.

Segundo Andrade (2010), as concepções de avaliação vão se apropriando ao momento histórico e cultural que a sociedade vai passando, tornando-se ainda cada vez mais forte, através da formação, da experiência, e do discurso sobre elas, causando desta forma ingerência na prática. 
Falar de avaliação nos remete ao entendimento e reflexão da amplitude da educação. Nesse sentido, a ideia que cada um traz sobre a avaliação está diretamente relacionada à sua própria concepção de educação, que muitas vezes se percebe distorcidos e enraizados a motivos históricos, sociais, e também pedagógicos e políticos.

Assim, julga-se necessário discutir as concepções sobre a prática avaliativa, que estão presentes dentro do contexto da escola, além da avaliação do processo de ensino-aprendizagem.

De acordo com Andrade (2010), quando se discute a avaliação, mas importante do que definir o conceito, é apreender o seu significado. Nesse, o quantitativo não deve sobrepor-se ao qualitativo. Dessa maneira o processo interessa mais do que a classificação dos alunos no final do ano letivo, por exemplo. Mas pensar a formação humana como prioritária à técnica interessa aos gestores de secretarias de educação? E estado? Si assim o fosse às avaliações externas não prezavam por sistemas de classificações do alunado, as verbas destinadas às escolas não estariam subordinadas ao rendimento dos alunos.

Não são poucas as definições encontradas quanto ao entendimento e conceito de avaliação. Isso porque essa não se resume apenas ao processo de realização de provas e de atribuição de notas. A avaliação é muito mais do que um registro de perguntas e respostas, a serem respondidas por alunos em tempos de provas (LUCKESI, 2003).

A avaliação é um objeto de ensino, que possibilita ao aluno mostrar seu desempenho e as competências adquiridas como resultados de sua aprendizagem, porém não pode se limitar a essa função. Serve também para o docente analisar sua práxis e melhorar suas estratégias metodológicas em sala de aula; bem como para a instituição de ensino, que através do conhecimento dos resultados, pode buscar o melhor caminho para solucionar os problemas apresentados ou continuar melhorando nos aspectos que estão produzindo bons resultados (HAYDT, 1997).

Segundo Sacristán (1998), a avaliação é o meio pelo qual alguma ou várias características do aluno, de um grupo de estudantes, de um ambiente, ou dos materiais educativos, professores, programas, são analisadas por alguém, na perspectiva de conhecer suas características e condições, seus limites e potencialidades, em razão de alguns critérios ou pontos de referência, para emitir um julgamento que seja relevante em termos educacionais.

Mesmo com os avanços ocorridos nas concepções de ensino e de aprendizagem e de avaliação, esta concepção limitada do processo avaliativo esteve por muito tempo, e ainda está arraigada na mente e nas práticas de muitos educadores, e, consequentemente, na de muitos alunos (RIBEIRO, 2011). 
Sabe-se que a aprendizagem, deve ser um meio que atua em um processo de formar e avaliar, que são indispensáveis e contribuem para um bom desenvolvimento, tendo a definição dos resultados do processo um dos aspectos mais importantes da vida do aluno (MENDEZ, 2002).

Hoffmann (2003) destaca a avaliação como um momento de o educando tomar consciência, como meio de conquistar um saber de si e, para o professor perceber as conquistas, descobertas dos alunos, bem como relatar o processo vivido em sua evolução.

Portanto, avaliar é propiciar momento de reflexão quanto aos conteúdos, quanto às técnicas de ensino, a relação educador - educando, é momento que proporciona a tomada de consciência de que a avaliação não é apenas uma pesquisa que visa números e percentuais, mas sim o aprendizado pleno, feito por todas as partes mencionadas anteriormente.

\section{Avaliação: diagnóstica, formativa e somativa}

Sabendo que a avaliação da aprendizagem é um componente indispensável do processo educativo, é fundamental que haja um acompanhamento do desenvolvimento do educando ao longo da construção do seu conhecimento. Existem diferentes classificações de avaliação, para nosso estudo consideramos três funções: diagnóstica, formativa e somativa (HAYDT, 1997).

A avaliação formativa é realizada com a finalidade de informar o professor e o aluno sobre o resultado da aprendizagem, durante o desenvolvimento das atividades escolares, identificando as possíveis dificuldades do ensino-aprendizagem, de forma a possibilitar reformulações no mesmo e assegurar o alcance dos objetivos.

Perrenoud (1999) aborda a necessidade de uma abordagem pragmática da avaliação formativa, apontando que ajuda o aluno a aprender e se desenvolver, ou melhor, que participa da regulação das aprendizagens e do desenvolvimento no sentido de um projeto educativo.

É através da avaliação formativa que o aluno toma conhecimento dos seus erros e acertos e encontra estimulo para um estudo sistemático. Essa modalidade de avaliação possibilita uma autoavaliação tanto do aluno como do professor. É motivadora porque evita as tensões causadas pelas avaliações corriqueiras que geram mais tensão do que reflexão.

Segundo Haydt (1997), a avaliação somativa tem como função classificar os alunos ao final da unidade, semestre ou ano letivo, segundo níveis de aproveitamento apresentados. A avaliação somativa promove a definição de escopos, frequentemente se baseia nos conteúdos e procedimentos de medida, como provas e teste objetivo. 
Conceituar a função somativa é relaciona-se com mecanismos de domínio do aluno em áreas especificas do conhecimento, fragmentadas de aprendizagem, permitindo atribuir uma capacidade utilitária que por sua vez, pode ser utilizada como classificação e instrumento de domínio escolar.

Baseando-se em Kraemer (2005), a avaliação somativa pretende ajuizar o progresso realizado pelo aluno no final de uma unidade de aprendizagem, no sentido de aferir resultados já colhidos por avaliações formativas e obter indicadores que permitem aperfeiçoar o processo de ensino.

Esse tipo de avaliação associa-se diretamente a função classificatória ao final de um período de aprendizagem, fazendo com que os alunos alcancem um propósito direto e uma visão de conjunto, verificando quais objetivos atingidos e considerando-se o padrão de aprendizagem desejável.

A terceira concepção de avaliação, a avaliação diagnóstica é constituída por uma sondagem, projeção e retrospecção da situação de desenvolvimento do aluno, dando-lhe elementos para verificar o que e como aprendeu. Essa modalidade fornece ao educador informações para que possa pôr em exercício a idealização de forma adaptada às características de seus educandos.

A avaliação da aprendizagem é um desafio que requer novas atitudes e mudanças do professor. Por isso, requer do educador a busca pela inovação, exige uma mudança na postura deste profissional tanto em relação à avaliação propriamente dita, à educação e a sociedade que o limita.

É por meio das metodologias e dos processos avaliativos utilizados que o professor irá participar da reprodução ou transformação da sociedade na qual estamos inseridos, podendo formar, ou não, sujeitos críticos e emancipados para que possam nela conviver com equidade.

Esse contexto nos leva a concluir que, sendo a avaliação um meio imprescindível para a aprendizagem, o processo educativo deve apontar para a construção de uma prática avaliativa qualitativamente mais significativa, comprometida com a aprendizagem e, consequentemente, com o desenvolvimento humano e intelectual do educando.

\section{Metodologia}

Com o intuito de atingir os objetivos traçados, a metodologia utilizada caracterizou-se por uma investigação de campo com uma abordagem qualitativa. Minayo (2014) afirma que a 
abordagem qualitativa permite descobrir processos sociais ainda pouco conhecidos relativos a grupos particulares, com a revisão e a criação de novos conceitos e categorias durante a pesquisa.

O universo da pesquisa foi formado por oito $(n=8)$ professores que ministram aulas de Educação Física no ensino médio na rede pública estadual de ensino do município de Sobral/CE.

Os docentes foram convidados a participar da pesquisa pela autora do estudo em seus ambientes de trabalho, depois da devida autorização da Escola. Na oportunidade, foram explicados os objetivos da pesquisa e os procedimentos para a coleta dos dados, bem como a solicitação para a realização da pesquisa através do Termo de Consentimento Livre e Esclarecido (TCLE). Vale reforçar que os participantes tiveram sua identidade preservada, e foram identificados utilizando-se se os seguintes códigos para designar professor um, professor dois, sucessivamente, como se segue: P1, P2, P3, P4, P5, P6, P7, P8.

A técnica escolhida para realizar a coleta de dados foi a entrevista estruturada a partir da elaboração de um roteiro com perguntas abertas. As narrativas foram registradas com o auxílio de um gravador após autorização prévia dos participantes.

Foi utilizada a análise temática proposta por Minayo (2014) para o tratamento dos dados obtidos na entrevista. Segunda a autora, fazer uma análise temática consiste em descobrir os núcleos de sentido que compõem uma comunicação, cuja presença ou frequência signifiquem alguma coisa para o objeto analítico visado (MINAYO, 2014).

A pesquisa respeita os aspectos éticos da Resolução 466/12, do Conselho Nacional de Saúde, que define as normas para pesquisa com seres humanos, considerando o respeito pela dignidade humana, à proteção dos princípios éticos aos participantes das pesquisas científicas (BRASIL, 2012).

\section{Resultados e Discussão}

Com base na análise das entrevistas realizadas foi possível organizar os dados em duas categorias temáticas, seguindo as referências pautadas na análise temática de Minayo (2014). Os depoimentos foram organizados em duas categorias elaboradas a partir das falas dos sujeitos da pesquisa: Avaliação da aprendizagem e Avaliação na Educação Física escolar. 


\section{Avaliação da aprendizagem}

Na primeira pergunta os docentes foram questionados sobre a concepção de avaliação, os professores fornecem respostas distintas. Essas diferentes concepções, de certo modo, produzem diferentes maneiras de intervenção no processo ensino-aprendizagem, como se observa nas falas:

Entendo avaliação enquanto um processo que fornece potencialidades $e$ dificuldades tanto para o professor como para o aluno. Buscando assim subsídios para melhorar o ensino aprendizagem (Pl).

É uma ferramenta de verificar dados para que assim possamos manter ou adaptar às metas para um resultado (P2).

A avaliação é uma forma de verificar o processo de ensino-aprendizagem (P8).

As respostas foram interpretadas em dois núcleos, a saber, as que definem avaliação como meio de atribuição de notas, verificação de aprendizagem dos conteúdos ou verificação da capacidade intelectual do aluno, ou seja, a avaliação sendo vista como um instrumento de verificação como se percebe nas falas de P2 e P8; e as que definem a avaliação como um instrumento de reflexão e possibilidades sobre a prática educativa, a saber: P1.

Luckesi (2003) destaca que o papel da avaliação é diagnosticar a situação da aprendizagem, tendo em vista subsidiar a tomada de decisão para a melhoria da qualidade do desenvolvimento do educando. Na medida em que busca meios pelos quais todos possam aprender o que é necessário para o próprio desenvolvimento, deixa de ser um ato seletivo. Sendo assim, ela inclusiva é, antes de tudo, é um ato amoroso.

Conforme o autor supracitado, não podemos mais pensar a avaliação como um instrumento de autoritarismo e classificação, que decide sobre a aprovação ou reprovação do aluno. Nesse contexto, a nota torna-se um fim em si mesmo, ficando distanciada e sem relação com as situações de aprendizagens.

Para Haydt (1997), o processo de avaliação consiste em determinar em que medida os objetivos educacionais estão sendo atingidos e como visam a produzir mudanças de comportamento. Assim, mudar a nossa concepção se faz urgente e necessário. Devemos romper com padrões estabelecidos pela própria história de uma sociedade elitista e desigual.

Em seguida, os professores foram questionados sobre a função da avaliação no processo de ensino-aprendizagem. 
Identificar as fragilidades e potencialidades dos alunos durante o processo de ensino-aprendizagem (Pl).

Fornecer indicadores sobre a aprendizagem dos alunos (P5).

Tem que dar continuamente durante todo o ano letivo, diagnosticando $e$ garantindo que os alunos estão aprendendo (P6).

As respostas dos participantes evidenciaram a importância da avaliação na formação do alunado quando anunciam que esse artifício revela potencialidade e asseguram em processo continuo da aprendizagem.

Assim, a avaliação é um desafio que requer novas atitudes e mudanças do professor. Por isso, requer do educador a busca pela inovação, exige uma mudança na postura deste profissional tanto em relação à avaliação propriamente dita, quanto à educação e a sociedade que o limita.

Segundo Lima (2002), a avaliação deve buscar a identificação de avanços e aspectos a serem superados, bem como um procedimento que revele os processos de aprendizagem do indivíduo e que aponte os passos do desenvolvimento futuro.

Para que a avaliação suscite resultados satisfatórios à aprendizagem, o essencial é conhecer que tipo de discente está sendo avaliando e quais são suas verdadeiras necessidades; as estratégias usadas pelo professor; o apoio pedagógico da equipe gestora da escola também é primordial nesse processo.

Assim sendo, um processo que se paute em princípios mais formativos e menos instrutivos, mais emancipados e menos restritivos, enfim, um processo mais transformador e intervencionista e menos 'engessado' e burocrático.

\section{Avaliação da aprendizagem na educação física escolar}

Na segunda categoria, os professores foram questionados sobre a avaliação na Educação Física escolar.

Gosto de trabalhar com seminários e busco analisar as discussões, as colocações, experiências, dentre outros. Já com relação às vivências procuro observar a inclusão, os valores de respeito, confiança, cooperação, dentre outros (P1). 
Observação dos alunos no desenvolvimento motor, através de rodas de conversas sobre as dificuldades e desinteresse por práticas físicas, avaliações escritas onde eles expressam o seu senso crítico (P3).

Talvez por não repensar minha prática como algo construtivo, minha avaliação se dá apenas pela participação do aluno nas aulas práticas, conseguindo assim ao menos sua vivência nas atividades; já nas teóricas, provas objetivas e também a bagagem de informações que o aluno traz ao avançar de ano escolar (P10).

Identificamos nas falas dos professores entrevistados dois núcleos, a saber: P1 e P2 parecem realiza avaliação nas aulas de Educação Física de forma a contempla uma práxis indissociável entre teoria e prática e entre instrumento e a subjetividade do sujeito; já P10 distancia-se desse modo de pensar a avaliação ao afirmar não repensar a prática e por segregar o processo em momentos distintos de teoria e de prática. Esse último modo de realizar a avaliação não contempla a complexidade da mesma e revela pouco saber sobre o processo.

A avaliação tem um papel muito importante, ela nos dá subsídios para um questionamento, uma reflexão, advinda de diferentes tipos de avaliação, de modo complementar, ela pode ter características diferentes, mas atende vários objetivos é isso o que faz a diferença.

$\mathrm{Na}$ Educação Física, a avaliação deve proporcionar aos estudantes uma reflexão e análise sobre os conteúdos ensinados, com a finalidade de que o aluno construa seu conhecimento, o valor numérico é redimensionado, ou seja, torna-se consequência da aprendizagem do estudante.

Conforme Darido (2012), avaliar na Educação Física implica ajudar o aluno a perceber as suas facilidades, as suas dificuldades e, sobretudo, pretende ajudá-lo a identificar os seus progressos de tal modo que tenha condições de continuar avançando.

A avaliação na Educação Física, deve superar práticas tradicionais de ensino, pois já não cabe a ela verificar resultados obtidos pelo rendimento esportivo ou pela técnica de movimentos padronizados, com a finalidade de atribuir uma nota ao aluno através de testes quantitativos (FONTOURA et al., 2014).

A superação desse modelo requer dedicação e planejamento por parte dos professores, além de formação continuada que permita concepções de uma Educação Física reflexiva, que se preocupa com a formação integral do sujeito considerando no processo de avaliação as diferentes dimensões do ser discente. Além disso, esse parâmetro educacional requer que o 
profissional educador esteja inserido em uma práxis situada histórico-social no contexto escolar.

Por fim, os professores foram questionados sobre o que é necessário para se ter uma avaliação de qualidade na Educação Física.

Não só uma avaliação de qualidade, mas uma valorização da disciplina. Precisamos lutar pela valorização dessa disciplina que os estudantes tanto gostam, mas como um fim e não mero meio para outras disciplinas. A Educação Física tem seus conteúdos, seus critérios avaliativos, então ela precisa ser mais valorizada $(P 2)$.

Uma compreensão do meio social, que permita ao avaliador entender o indivíduo avaliado, troca de experiência e motivação para que assim sintamse desafiados a progredir (P4).

É fundamental que para exista qualidade a disciplina de Educação Física seja reconhecida como as demais áreas do conhecimento. Esse é o primeiro passo para alcançarmos qualidade (P7).

Como se pode observar, os professores destacam: a 'luta' P2; a 'compreensão do meio social' P4 e o 'reconhecimento' P7 como necessários para a valorização da disciplina de Educação Física e como ponto de partida para que o processo de ensino-aprendizagem na Educação Física desenvolva todos os elementos de uma prática pedagógica de forma exitosa, junto à avaliação.

A disciplina de Educação Física deve ser percebida como importante área de conhecimento, através da qual ao educando é ofertada a possibilidade de refletir sobre o movimento, sobre a tomada de consciência do corpo, a cultura do cotidiano, dentre outros aspectos.

O mesmo se aplica à avaliação escolar dessa disciplina no magistério, onde o professor pode, quando bem orientado e formado, acompanhar o desenvolvimento do aluno quanto à percepção e amadurecimento das relações com seu corpo em movimento, a complexidade social na qual faz parte, os valores e princípios formativos.

Hoffmann (2003) destaca a avaliação como um momento de o educando tomar consciência como meio de conquistar um saber de si e para o professor perceber as conquistas, descobertas dos alunos, bem como relatar o processo vivido em sua evolução.

Essa postura de percepção da avaliação escolar exige do professor de Educação Física, e de todos os demais profissionais em educação, uma mudança cultural onde, avaliação se 
mescla com o processo educativo, e não apenas constitui-se em um momento a parte e isolado do ato educacional (FROÉS JUNIOR, 2011).

Dessa forma, podemos inferir que a grande mudança a ser alcançada na educação transcende os muros da escola, e convida, a um envolvimento e comprometimento mais efetivo, toda a sociedade, os pais, os gestores e as entidades responsáveis pela educação, com o intuito de valorizar mais o papel do professor e acompanhar mais qualitativamente os dados avaliativos, que são mais do que meros números representativos.

\section{Considerações finais}

No contexto de educação mais atual a avaliação ganhou diversos moldes e novas perspectivas que são, cada vez mais, fundamentais para que se possam melhorar as práticas pedagógicas dos profissionais educadores.

Entretanto, a pesquisa nos mostrou que apesar das mudanças propostas nas últimas décadas no que se refere ao entendimento sobre avaliação escolar, ainda é possível identificar professores que possuem uma compreensão fragilizada sobre avaliação da aprendizagem. Evidenciamos ainda, que os professores possuem pouco conhecimento sobre a função da avaliação no processo de ensino-aprendizagem, dificultando, junto a outros fatores, o desenvolvimento exitoso no processo educacional.

Uma das funções dessa avaliação percebida como meio e não como fim, agrega-se a valor do trabalho do educador, que, nos dias atuais, requer acompanhar o processo como um todo, não apenas servindo à avaliação para perceber os educandos bons e ruins, ou seja, servir a um estado regulador. Nessa função, funda-se a percepção do todo, e da avaliação como algo que se insere no processo educacional, e não apenas como instância isolada do ato de educar.

Assim, considera-se a avaliação o momento que proporciona a tomada de consciência não apenas para visar números e percentuais, mas sim o aprendizado pleno do alunado, revelado em espaços e tempos determinados por contexto educacional que permeia a função docente e suas responsabilidades com a qualidade do ensino imbricado em relações micro e macro política, cultura e social.

Desta forma, faz-se necessário uma percepção global dos sujeitos na tentativa de apreendê-los em suas complexidades avaliativas. Não se deve desprezar as funções diagnósticas e somativas, pois complementares a função do trabalho do professor de Educação Física, porém é necessário compreende-las junto a outras estratégias de avaliação permanente, levando-se em 
conta as subjetividades e os estágios maturacionais do alunado. O sistema educacional ainda valoriza, como um todo, notas e melhores educandos, algo que será superado através do entendimento da avaliação em suas possibilidades e de uma mudança cultural que ainda poderá demandar muito tempo, uma vez que as mesmas ocorrem em uma terrenalidade lenta.

\section{REFERÊNCIAS}

ALEGRE, A. N. A avaliação em educação física: ação docente nas escolas oficiais de primeiro grau. 1993. 152 f. Dissertação (Mestrado em Educação Física) - Escola de Educação Física, Universidade de São Paulo, São Paulo, 1993.

ANDRADE, J. A. L. Avaliação da aprendizagem do discurso revelado à prática pedagógica: um estudo de caso numa escola de ensino médio em Maracanaú-CE. 2010. 173 f. Dissertação (Mestrado em Educação) - Faculdade de Educação, Universidade Federal do Ceará, Fortaleza, 2010.

BRACHT, V. Educação física e aprendizagem social. Porto Alegre: Magister, 1992.

BRASIL. Conselho Nacional de Saúde. Resolução n 466, de 12 de dezembro de 2012. Diretrizes e normas regulamentadoras de pesquisa envolvendo seres humanos. Brasília, 2012.

DARIDO, S. C. A avaliação da Educação Física na escola. In: UNIVERSIDADE ESTADUAL PAULISTA. Prograd. Caderno de formação: formação de professores didática geral. São Paulo: Cultura Acadêmica, p. 127-140, v. 16, 2012.

FONTOURA, T. B. et al. Avaliação escolar da Educação Física segundo a opinião de professores da rede estadual de ensino de Santa Maria. Educação Física em Revista, Brasília- DF, v. 8, n. 3, p. 01-09, 2014.

FRÓES JÚNIOR, E. G. et al. Avaliação: Desafios e Perspectivas para Educação Física Escolar. In: IV EDIPE - Encontro Estadual de Didática e Práticas de Ensino. 2011, Goiânia, Anais do IV EDIFE. 2011.

HADJI, C. Avaliação desmistificada. Porto Alegre: ArtMed, 2001.

HAYDT, R. C. C. Avaliação do processo ensino-aprendizagem. 6. ed. São Paulo: Ática, 1997.

HOFFMANN, J. Avaliação: mito e desafio. Uma perspectiva construtivista. 33. ed. Porto Alegre: Mediação, 2003.

KRAEMER, M. E. P. A avaliação da aprendizagem como processo construtivo de um novo fazer. Revista da Rede de Avaliação Institucional da Educação Superior, v. 10, n. 2, jun. 2005. 
LIBÂNEO, J. C. Didática. São Paulo: Cortez, 1994.

LIMA, E. S. Ciclos de formação: uma reorganização do tempo escolar. São Paulo:

Sobradinho 107, 2002.

LUCKESI, C. C. Avaliação da aprendizagem escolar. São Paulo: Cortez, 2003.

MENDEZ, J. M. A. Avaliar para conhecer, examinar para excluir. Porto Alegre: Artmed, 2002.

MINAYO, M. C. S. O desafio do conhecimento: pesquisa qualitativa em saúde. São Paulo: Hucitec, 2014.

PERRENOUD, P. Avaliação: da excelência à regulação das aprendizagens - entre duas lógicas. Porto Alegre: Artes Médicas, 1999.

RIBEIRO, E. A. G. Avaliação Formativa em Foco: Concepção e Características no Discurso Discente. 2011. 137f. Dissertação (Mestrado em Educação) - Universidade Estadual de Londrina, Londrina, 2011.

SACRISTAN, J. G. O currículo: uma reflexão sobre a prática. 3. ed. Porto Alegre: Artmed, 1998.

\section{Como referenciar este artigo}

FERNANDES, Maria Petrília Rocha.; SANTOS, Maria Adriana Borges dos.; NASCIMENTO, Kessiane Fernandes.; RIBEIRO, Manoela de Castro Marques.; FERREIRA, Heraldo Simões. Avaliação da aprendizagem: reflexões dos professores de Educação Física na Educação Básica. Revista on line de Política e Gestão Educacional, Araraquara, v. 23, n. 2, p. 286-305, maio/ago., 2019. E-ISSN:1519-9029. DOI: 10.22633/rpge.v23i2.11541

Submetido em: 08/07/2018

Revisões requeridas: 26/09/2018

Aprovado em: 15/10/2019

Publicado em: 06/03/2019 